\title{
Development of UWB Bandpass Filter with Two Notch Bands to Reject IEEE 802.11a/b Services
}

\author{
Thirumalaivasan $\mathrm{K}$ and Nakkeeran $\mathrm{R}$
}

\begin{abstract}
This paper presents an Ultra-Wideband (UWB) bandpass filter with two notched bands for avoiding interference between the UWB radio system and the existing radio systems. This novel UWB dual notch filter is based on microstrip structure which consists of ring resonator and interdigital coupling. The dual notched bands operation is implemented by integrating folded stubs in the inter-digital coupled microstrip conductors. The structure generates two distinct resonant frequencies to stop $2.4 \mathrm{GHz}$ and $5 \mathrm{GHz}$ Wireless Local Area Network (WLAN) services. The resonance of each stub introduces a narrow rejection band in the UWB passband which then results in dual notched bands. The notched band can be shifted to any other desired frequency by tuning the length of the stub. Simulation, design, fabrication and measurement of the proposed UWB bandpass filter with notched bands are carried out strictly following the FCC's spectrum mask. The filter demonstrated both excellent ultra-wide bandwidth (from $1.8 \mathrm{GHz}$ to $7.8 \mathrm{GHz}$ ) and rejection performance of $-41 \mathrm{~dB}$ at $2.6 \mathrm{GHz}$ and $-24 \mathrm{~dB}$ at $5.3 \mathrm{GHz}$. The designed filter is successfully simulated using electromagnetic simulator, IE3D. The overall size of the developed filter with the above features is $6 \mathrm{~mm}$ (length) $\times 39.2 \mathrm{~mm}$ (height) $\times 1.6 \mathrm{~mm}$ (height). The measured insertion loss and group delay of the developed filter over the desired passband is at acceptable level.
\end{abstract}

Index Terms-Ultra wideband filter, WLAN, multiple-mode resonator, microstrip coupling structure, notched filter.

\section{INTRODUCTION}

Today, the most widespread WLAN protocols are IEEE $802.11 \mathrm{~b} / \mathrm{a}$, which utilize $2.4 \mathrm{GHz}$ and $5 \mathrm{GHz}$ ISM frequency bands respectively. As a result of such availability, many WLAN providers are interested in offering access to these frequency bands [1-4]. These narrowband signals are potential interferer to introduce interference to the UWB receivers so that the desired throughput performance is degraded in the UWB systems. As UWB systems operate in a very large bandwidth with low power spectral density, they share the spectrum with other existing systems resulting interferences [5-7]. It is desired to implement UWB systems with a provision for the suppression of the strong narrow-band signals from WLAN systems. Notch filters are the right entrant to combat this type of circumstances [8].

Notch filters are one of the key components of radio transceiver in a dual band wireless communication system. A single band suppression notch filter cannot fulfill the filtering requirements for receivers operating in multi-service

Manuscript received November 24, 2010; revised May 4, 2011.

Thirumalaivasan K, Research scholar is with Pondicherry engineering College, Puducherry, India. (e-mail: thirumalaivasank@pec.edu).

Nakkeeran R, Associate Professor is with Pondicherry Engineering College, Puducherry, India (e-mail: rnakeeran@pec.edu). environment [9]. Therefore, filter with multiple notches is required solution to this problem. Significant research activities are being carried out to explore various UWB notch filters for short-range multi-service systems. These notch filters can play an important role in improving the overall performance of the UWB system [8-10]. Due to the rapid growth in broadband systems, the requirements for filter design become inevitable. In recent years, several techniques such as multilayer liquid crystal polymer technology (LCP) [11] and ceramic ball grid array package (BGA) [12] have been proposed for designing this type of filter. Most of the reported filters are based on multilayer structures, which require complicated synthesis procedure, high expenditure, and cumbersome troubleshooting. Also, the associated inductance of the electrical conductor causes unwanted distortion to the signals when the electrical length of the conductor is very small. To overcome above said problems, a compact and low cost UWB notch filter based on ring resonator with interdigital coupling is proposed, developed and tested. For easy integration with Printed Circuit Board (PCB), filter is designed and fabricated on FR4 substrate whose dielectric constant is 4.4 and thickness $1.6 \mathrm{~mm}$. They are characterized and optimally designed using the electromagnetic (EM) simulator IE3D, which is part of the Zeland software package [13].

The paper is organized as follows: In Section II, UWB notch filter geometry using ring structure with two open stubs is described. Results and discussions are presented in Section III. Section IV concludes the paper.

\section{UWB DUAL NotCh FILTER GEOMETRY}

The UWB dual notch filter consists of feed lines, coupling gaps, and ring resonator. The geometry of the filter structure is shown in Fig.1, where a ring with its interdigital-coupled conductors is integrated with microstrip conductor. The size of the stubs is optimized to achieve notches at $2.6 \mathrm{GHz}$ and $5.3 \mathrm{GHz}$.

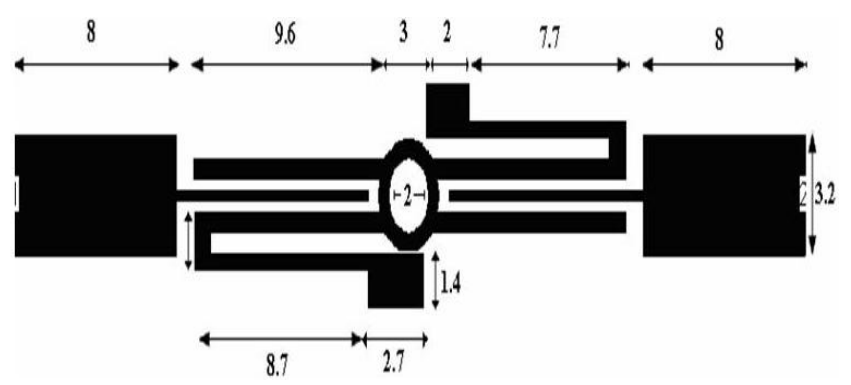

Fig. 1 UWB dual notch filter with open stubs (All dimensions are in $\mathrm{mm}$ ) 
The interdigital feed-lines used here can enhance the coupling degree between the ring resonator and the feed-lines. This coupling can be adjusted to control the bandwidth. Thereby, the ring resonator and the symmetrical interdigital feed-lines can work together to make up the desired UWB bandpass filter. The top open stub shown in Fig. 1, above the ring geometry is responsible for introducing notch at $2.6 \mathrm{GHz}$ (Notch 1). To inhibit the signals ranging from $5.1 \mathrm{GHz}$ to $5.3 \mathrm{GHz}$ (Notch II), stepped-impedance folded open stub is integrated below the ring structure as shown in Fig.1.

Several techniques for providing zero transmission or band rejection on microstrip structure have been demonstrated such as defect ground structure (DGS), photonic bandgap, split ring resonator, spur-line structure, slot resonator [14-20] etc. However, for narrow bandwidth rejection and easy fabrication the quarter wavelength open stub is a good solution. In this paper high performance and compact UWB notch filter based on ring resonator with interdigital coupling is designed, fabricated and demonstrated. The electrical length is close to $90^{\circ}$ and the coupling gap is $0.3 \mathrm{~mm}$ for the proposed structure.

\section{RESULTS AND DISCUSSIONS}

Simulation has been carried out using IE3D, which is a full wave electromagnetic simulator. The simulation ' $S$ ' parameters of the proposed dual notch filter are shown in Fig. 2. The proposed UWB notch filter has three transmission bands. The first passband ranges from $1.9 \mathrm{GHz}$ to $2.3 \mathrm{GHz}$ has $-1 \mathrm{~dB}$ insertion loss with $-11 \mathrm{~dB}$ return loss. The second passband from $3.1 \mathrm{GHz}$ to $5.1 \mathrm{GHz}$ has $-0.5 \mathrm{~dB}$ insertion loss with $-35 \mathrm{~dB}$ return loss. Finally, the third pass band ranges from $5.8 \mathrm{GHz}$ to $7.8 \mathrm{GHz}$ with insertion loss of $-7 \mathrm{~dB}$ and return loss $-16 \mathrm{~dB}$.

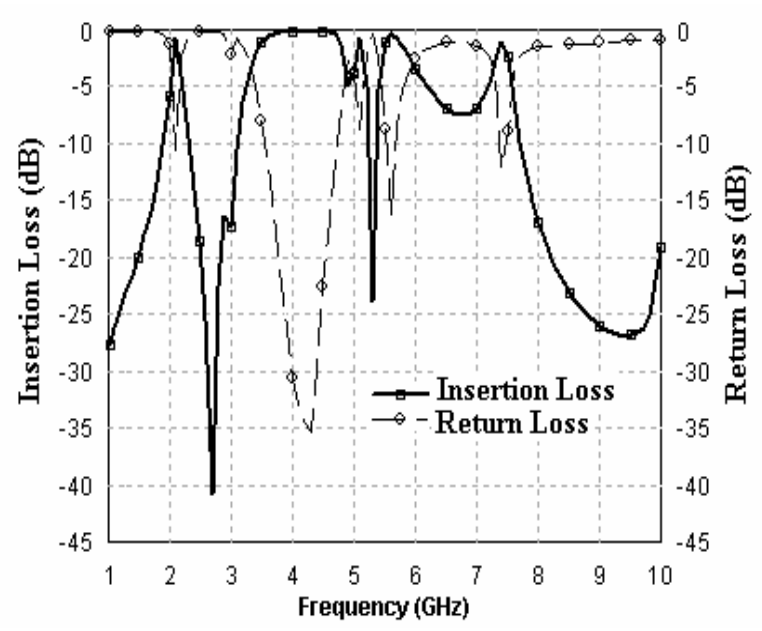

Fig. 2 Simulation S parameters of UWB dual notch filter

The proposed filter demonstrated both ultra-wide bandwidth (from $1.8 \mathrm{GHz}$ to $7.8 \mathrm{GHz}$ ) and rejection performance. The first rejection is achieved for $2.4 \mathrm{GHz}$ WLAN with better insertion loss of $-41 \mathrm{~dB}$. The second rejection is achieved for $5 \mathrm{GHz}$ WLAN with the insertion loss of $-24 \mathrm{~dB}$. This filter can be integrated with UWB radio systems and efficiently enhance the interference immunity.

Flat group delay or linear phase is necessary to avoid distortion in the baseband signals. The simulation group delay noticed for the UWB dual notch is below $0.4 \mathrm{~ns}$ in all operating regions as shown in Fig. 3. Fig. 4 shows the phase simulation of $S_{21}$ for UWB dual notch filter that is acceptably linear for UWB applications. Its photograph is shown in Fig.5.

As shown in Fig. 5, two $50 \Omega$ transmission lines are extended to accommodate the SMA connectors to connect to the scalar network analyzer for measurement and measured results of notch filter are given in Figures 6, 7 and 8. They are comparable to simulated results. The small discrepancy between them might be due to fabrication tolerance, loss tangent of the substrate and parasitic effect of the SMA connectors. Using Hewlett Packard Network analyzer (HP8757D), the insertion loss, return loss and group delay for the developed filters are measured.

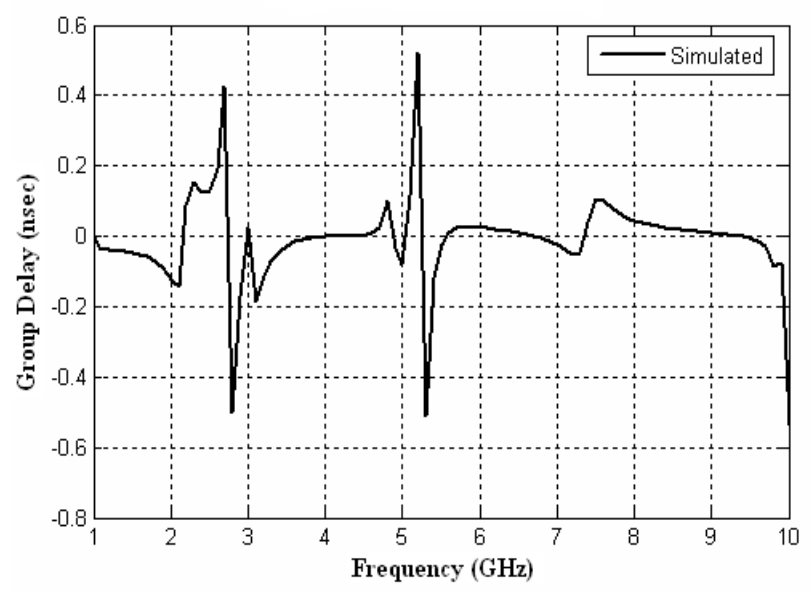

Fig. 3 Simulation group delay of UWB dual notch filter

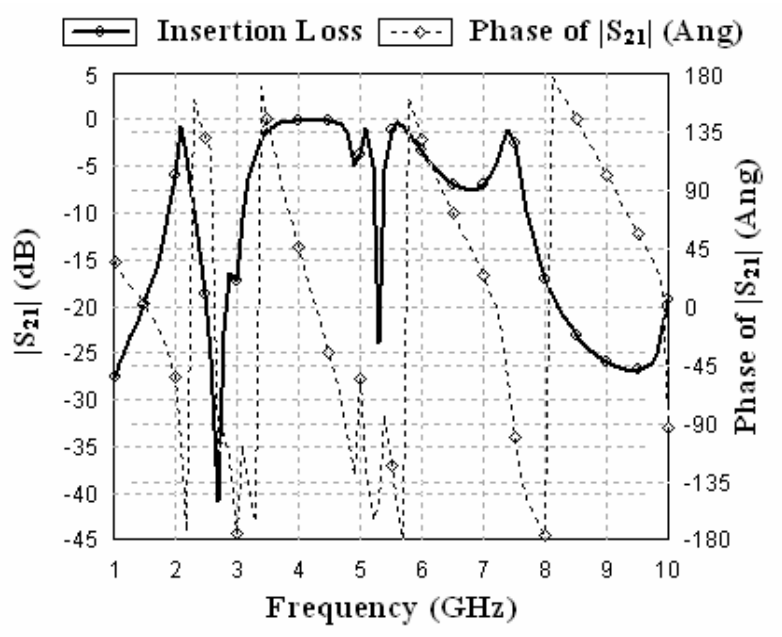

Fig. 4 Simulation phase response of UWB dual notch filer

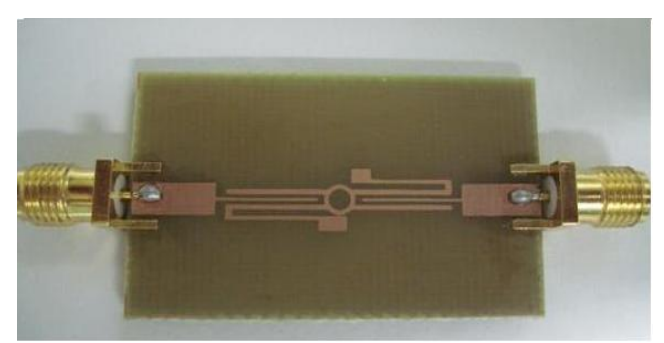

Fig. 5 Prototype of UWB dual notch filter 


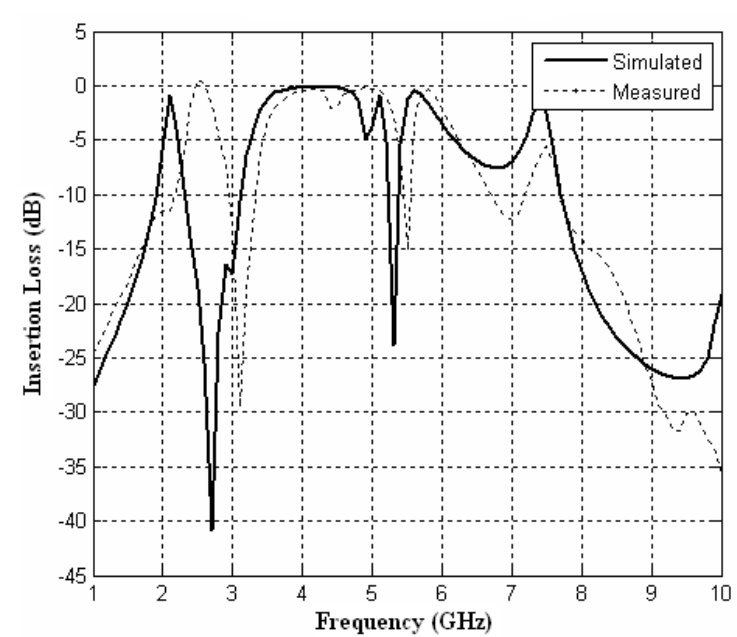

Fig. 6 Simulated and measured insertion loss of UWB dual notch filter

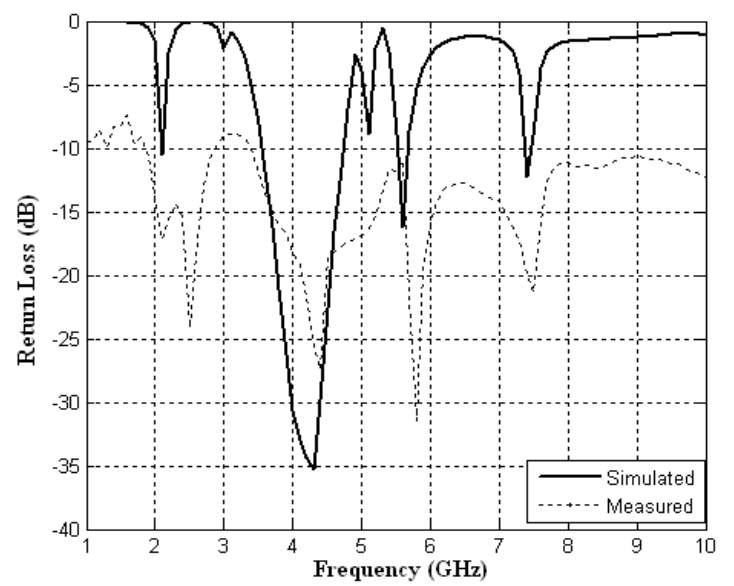

Fig. 7 Simulated and measured return loss of UWB dual notch filter

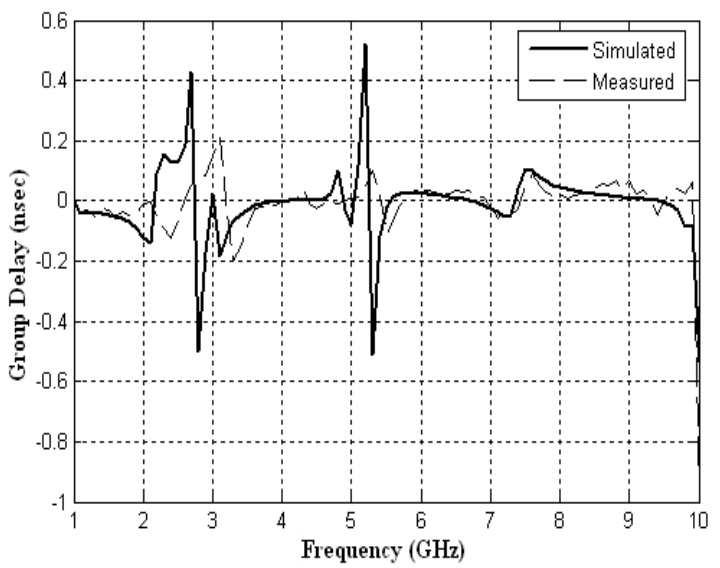

Fig. 8 Simulated and measured group delay of UWB dual notch filter

The UWB bandpass filter with $2.4 \mathrm{GHz}$ and $5-6 \mathrm{GHz}$ rejection bands' performance parameters like insertion loss, return loss, passband of the filters, group delay, phase response and physical size are consolidated in Table I.

TABLE I: COMPARISON OF FILTER PARAMETERS

\begin{tabular}{|c|c|c|c|c|}
\hline Notch Filter & \multicolumn{2}{|l|}{ Simulation } & \multicolumn{2}{|c|}{ Measurement } \\
\hline \multirow{3}{*}{ Insertion loss (dB) } & $\begin{array}{l}\text { at passband I : } \\
1.9-2.3 \mathrm{GHz}\end{array}$ & -1 & $\begin{array}{l}2.1-2.9 \\
\mathrm{GHz}\end{array}$ & -1 \\
\hline & $\begin{array}{l}\text { at passband II: } \\
3.1-5.1 \mathrm{GHz}\end{array}$ & -0.5 & $\begin{array}{l}3.3-5.4 \\
\mathrm{GHz}\end{array}$ & -1 \\
\hline & $\begin{array}{l}\text { at passband III: } \\
5.8-7.8 \mathrm{GHz}\end{array}$ & -7 & $\begin{array}{l}5.6-70 \\
\mathrm{GHz}\end{array}$ & -12 \\
\hline
\end{tabular}

\begin{tabular}{|l|l|c|l|}
\hline \multirow{2}{*}{$\begin{array}{l}\text { Rejection } \\
\text { Performance }\end{array}$} & Notch I & $\begin{array}{c}-41 \mathrm{~dB} \\
\text { at } 2.6 \mathrm{GHz}\end{array}$ & $\begin{array}{l}-30 \mathrm{~dB} \\
\text { at } 2.6 \mathrm{GHz}\end{array}$ \\
\cline { 2 - 4 } & Notch II & $\begin{array}{c}-24 \mathrm{~dB} \\
\text { at } 5.3 \mathrm{GHz}\end{array}$ & $\begin{array}{l}-15 \mathrm{~dB} \\
\text { at } 5.3 \mathrm{GHz}\end{array}$ \\
\hline Return Loss (dB) & $-35 \mathrm{~dB}$ at $4.3 \mathrm{GHz}$ & $\begin{array}{l}-31 \mathrm{~dB} \\
\text { at } 4.5 \mathrm{GHz}\end{array}$ \\
\hline Group Delay (ns) & below 0.4 & below 0.4 \\
\hline Phase at passband & linear & linear \\
\hline Size $\left(\mathrm{mm}^{3}\right)$ & $6 \times 39.2 \times 1.6$ & $6 \times 39.2 \times 1.6$ \\
\hline
\end{tabular}

\section{CONCLUSION}

A ring resonator based UWB dual notch filter using microstrip structure, with wide passband, low insertion loss, better return loss and flat group delay, is verified in this paper. In order to achieve notches at $2.6 \mathrm{GHz}$ and $5.3 \mathrm{GHz}$, two folded open stubs are integrated with interdigital coupler nearby ring resonator. The developed filters demonstrated both excellent ultra-wide bandwidth (from $1.8 \mathrm{GHz}$ to $7.8 \mathrm{GHz}$ ) and rejection performance of $-40 \mathrm{~dB}$ at centre frequency of IEEE $802.11 \mathrm{~b}$ and $-24 \mathrm{~dB}$ at centre frequency of IEEE 802.11a. The group delay obtained for notch filter is about $0.4 \mathrm{~ns}$. The measured results are in good agreement with simulation ones. The notch bandwidth at $2.6 \mathrm{GHz}$ and 5.3 $\mathrm{GHz}$ is more than sufficient for suppressing the interference from IEEE $802.11 \mathrm{a} / \mathrm{b}$ services. With the all above features the dimension of the developed notch filter is around 6 (length) x 39.2 (height) x 1.6 (width) $\mathrm{mm}^{3}$.

\section{REFERENCES}

[1] Federal Communications Commission, FCC Report and Order, ET Docket 98-153, "Revision of Part 15 of the Commission's Rules Regarding Ultra- Wideband Transmission Systems," Feb. 14, 2002.

[2] A. Saito, H. Harada, and A. Nishikata, "Development of band pass filter for ultra wideband (UWB) communication," Proc. IEEE Conf Ultra Wideband Systems Technology, 2003, pp. 76-80.

[3] Hong, J. S. and M. J. Lancaster, Microstrip Filters for RF/Microwave Application, Wiley, New York, 2001.

[4] Pozar, D. M., Microwave Engineering, Wiley, New York, 1998.

[5] Mattaei. G. L, Young, and E. M. T. Jones, Microwave Filters, Impedance-Matching Networks, and Coupling Structures, Artech House, Norwood, MA, 1980

[6] H. Wang, L. Zhu, and W. Menzel, "Ultra-wideband bandpass filter with hybrid microstrip/CPW Structure," IEEE Microw. Wireless Compon. Lett., vol. 15, no. 12, pp. 844-846, Dec. 2005.

[7] L. Zhu, S. Sun, and W. Menzel, "Ultra-wideband (UWB) bandpass filters using multiple-mode resonator," IEEE Microw. Wireless Compon. Lett., vol. 15, no. 11, pp. 796-798, Nov. 2005.

[8] S. Sun and L. Zhu, "Capacitive-Ended interdigital coupled lines for UWB bandpass filters with improved out-of-band performances," IEEE Microw. Wireless Compon. Lett., vol. 16, no. 8, pp. 440-442, Aug. 2006.

[9] Boon Tiong Tan, Siou Teck Chew, Mook Seng Leong and Ban Leong Ooi, "A Dual-mode bandpass filter with enhanced capacitive perturbation," IEEE Trans. Microwave Theory Tech., MTT-51, pp.1906-1910, Aug. 2003.

[10] W. M. P. Feil, "Ultra-Wideband (UWB) filter with WLAN notch," Proceedings of the 36th European Microwave Conference, pp. 595-598, Manchester, UK, Aug. 2006.

[11] Zhang-Cheng Hao and Jia Cheng Hong, "Compact UWB filter with double notch bands using multilayer LCP technology," IEEE Microw. Wireless Compon. Lett., vol. 19, no. 8, pp. 500-502, Aug. 2009. 
[12] Yue Ping Zhang and Mei Sun, "Dual-band microstrip bandpass filter stepped impedance resonators with new coupling scheme," IEEE Trans Microw. Theory Tech., vol. 54, no. 10, Oct. 2006.

[13] IE3D Software Release -14, Developed by M/s Zeland Software Inc.

[14] Cheng-Ying Hsu, Lung-Kai Yeh, Chu-Yu Chen and Huey-Ru Chuang, "A 3-10 GHz Ultra-Wideband Bandpass Filter with 5-6GHz Rejection Band," Proceedings of Asia-Pacific Microwave Conference 2007

[15] Wong, S. W. and L. Zhu, "EBG-embedded multiple-mode resonator for UWB bandpass filter with improved upper-stopband performance," IEEE Microw. Wireless Compon. Lett., vol. 17, no. 6, 421-423, June 2007.

[16] Singh, P. K., S. Basu, andY. H. Wang, "Planar ultra-wideband bandpass filter using edge coupled microstrip lines and stepped impedance open stub," IEEE Microw. Wireless Compon. Lett. Vol. 17, No. 9, 649-651, Sep. 2007.

[17] Young-Hoon Chun, Hussein Shaman, and Jia-Sheng Hong, "Switchable Embedded Notch Structure for UWB Bandpass Filter," IEEE Microw. Wireless Compon. Lett, vol. 18, no. 9, Sep. 2008.

[18] J.-S. Park, J.-S. Yun, and D. Ahn, "A design of the novel coupled line bandpass filter using defected ground structure with wide stopband performance," IEEE Trans. Microwave Theory Tech., vol. 50, pp. 2037- 2043, Sept. 2002.

[19] F. Yang, K. Ma, Y. Qian, and T. Itoh, “A uniplanar compact photonic bandgap (UC-PBG) structure and its applications for microwave circuits," IEEE Trans Microw. Theory Tech., vol. 47, no. 11, pp. 15091514, Nov. 1999.

[20] C-Y. Hsu, C-Y. Chen and C-H. Huang, "A UWB filter using a dual-mode ring resonator with spurious passband suppression," Microwave Journal, vol. 48, no. 11, Nov.2005.

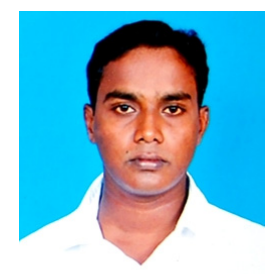

Mr. K. Thirumalaivasan was born in India. $\mathrm{He}$ received the B.Tech. degree in Electronics and Communication Engineering from Pondicherry University, Puducherry, India, and the M.E. degree in Communication Systems from College of Engineering Guindy, Anna University, Chennai, India, in 2004 and 2007 respectively. $\mathrm{He}$ is currently working towards the Ph.D degree at Pondicherry Engineering College, Pondicherry. His current research interest is in the area of UWB filters and narrowband interference issues with UWB systems.

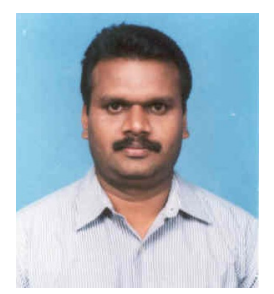

Dr. R. Nakkeeran received BSc. degree in Science and B.E degree in Electronics and Communication Engineering from the Madras University in 1987 and 1991 respectively and M.E degree in Electronics and Communication Engineering (with diversification in Optical Communication) from the Anna University in 1995. $\mathrm{He}$ received Ph.D degree from Pondicherry University in 2004. Since 1991, he has been working in the teaching profession. Presently, he is Associate Professor in Pondicherry Engineering College. He is life member of IETE, ISTE, OSI and IE(I). Also he is member of OSA, SPIE and IEEE. He has published more than hundred papers in National and International Conference Proceedings and Journals. He has co-authored a book, published by PHI. His areas of interest are Optical Communication, Networks, Antennas, Electromagnetic Fields and Wireless Communication. 